Published in final edited form as:

Curr Opin Crit Care. 2015 June ; 21(3): 209-214. doi:10.1097/MCC.0000000000000202.

\title{
Neurological prognostication after cardiac arrest
}

\author{
Claudio Sandronia and Romergryko G. Geocadin ${ }^{b, c}$ \\ aDepartment of Anesthesiology and Intensive Care, Catholic University School of Medicine, \\ Rome, Italy \\ bDivision of Neurosciences Critical Care Medicine, Departments of Neurology and Neurosurgery \\ 'Department of Anesthesiology and Critical Care Medicine
}

\begin{abstract}
Purpose of review-Prediction of neurological prognosis in patients who are comatose after successful resuscitation from cardiac arrest remains difficult. Previous guidelines recommended ocular reflexes, somatosensory evoked potentials and serum biomarkers for predicting poor outcome within $72 \mathrm{~h}$ from cardiac arrest. However, these guidelines were based on patients not treated with targeted temperature management and did not appropriately address important biases in literature.
\end{abstract}

Recent findings-Recent evidence reviews detected important limitations in prognostication studies, such as low precision and, most importantly, lack of blinding, which may have caused a self-fulfilling prophecy and overestimated the specificity of index tests. Maintenance of targeted temperature using sedatives and muscle relaxants may interfere with clinical examination, making assessment of neurological status before $72 \mathrm{~h}$ or more after cardiac arrest unreliable.

Summary-No index predicts poor neurological outcome after cardiac arrest with absolute certainty. Prognostic evaluation should start not earlier than $72 \mathrm{~h}$ after ROSC and only after major confounders have been excluded so that reliable clinical examination can be made. Multimodality appears to be the most reasonable approach for prognostication after cardiac arrest.

\section{Keywords}

cardiac arrest; prognostication; post-anoxic brain injury

\section{Introduction}

Despite recent improvement in post-resuscitation care, about $50 \%$ of patients resuscitated from cardiac arrest die or have poor neurological outcome due to severe post-anoxic brain injury [1]. The overall goal of prognostication has to focus on the best interest of the

\footnotetext{
Corresponding Author. Dr Romergryko G. Geocadin, Associate Professor, Division of Neurosciences Critical Care, Departments of Anesthesiology/Critical Care Medicine, Neurology and Neurosurgery, The Johns Hopkins University School of Medicine, 600 North Wolfe Street, Phipps 455, Baltimore, MD 21287, USA., Tel: +1 410955 7481; fax: +1 410614 7903, rgeocad1@ @hmi.edu.

Conflicts of Interest

Claudio Sandroni is first author of two systematic reviews and of the ERC-ESICM Advisory Statement on prognostication after cardiac arrest. Romergryko G. Geocadin is chair of the American Academy of Neurology Guidelines Writing Group on Reducing Brain Injury after CPR.
} 
patients: on one hand we want to avoid inappropriate treatment in patients with no chance of recovery, but on the other hand we also try not to withhold treatments prematurely in those that have a chance for good neurologic outcome.

\section{Definitions of neurological outcome after cardiac arrest}

In prognostication studies, investigators usually dichotomize neurological outcome as good or poor. However, while there is little doubt that vegetative state or death, corresponding to Cerebral Performance Categories (CPC)[2] 4 or 5, respectively, represent a poor outcome, the identification of severe neurological disability (CPC 3) with poor outcome has been less consistent. While most of the oldest studies on prognostication restricted poor outcome to CPC 4 and 5 [3], the majority of studies conducted after 2005 includes CPC 3 among poor outcomes and dichotomize CPC as 1-2 vs. 3-5[4], consistently with the latest update of the ILCOR Utstein Registry Templates for cardiac arrest and resuscitation outcome reports[5]. The CPC 3 includes a wide range of cerebral disabilities, from important memory loss to dementia and minimally conscious states which generally preclude an autonomous existence outside specialized institutions. The appropriateness of defining CPC 3 as poor outcome may depend on the timing when outcome is measured. In fact, some patients who are classified as having a CPC 3 at discharge may improve to a better performance category during the first three months after cardiac arrest [6].

A CPC $=5$ does not necessarily coincides with a poor neurological outcome at the time of death when no distinction is made between death due to neurological causes, as brain death, and death due other causes such as cardiac arrhythmias, which may occur after the patient has recovered from neurological injury. To avoid this ambiguity, when reporting neurological outcome the best CPC achieved during the patient's hospital stay should be reported [7]. Also, since most of the deaths due to severe brain injury in resuscitated patients occur indirectly, i.e. because of withdrawal of life sustaining treatment (WLST) rather than because of brain death $[8,9]$, the cause of death, as cardiac, neurological or other, should be reported in detail.

\section{Prognostication in patients treated with controlled temperature}

Until recently, the vast majority of evidence concerning prognostication after cardiac arrest was based on studies conducted in patients not treated with controlled temperature. After the advent of therapeutic hypothermia (TH) for the management of resuscitated comatose patients the use of sedation and muscle paralysis during the first $48 \mathrm{~h}$ after recovery of spontaneous circulation (ROSC) has become routine in order to facilitate control of body temperature. This may have introduced a potential source of interference in prognostication. In fact, both TH itself and sedatives and muscle relaxant agents used to maintain it may depress clinical reactivity, possibly making results of predictive indexes to appear worse than they are[10]. The effect of both sedative agents and muscle relaxants is prolonged in patients treated with controlled temperature because hypothermia reduces the drug clearance[11-13]. Before performing clinical examination, residual effects of sedation or neuromuscular blockade must be excluded[14]. 


\section{Type of prognostic indexes}

Four main categories of tests are used to predict poor outcome in comatose resuscitated patients. These include 1) clinical examination; 2) electrophysiological indexes; 3) serum biomarkers and 4) neuroimaging studies.

\section{Clinical examination}

Results of clinical examinations are usually unreliable in the first days after resuscitation. In particular, the absence of pupillary light reflex at ROSC is associated with false prediction of poor outcome in about one third of patients [15]. Reliability of these signs increase during the first $72 \mathrm{~h}$ after arrest in patients not treated with controlled temperature, and it reaches a maximum at three days from ROSC [3, 6]. In TH-treated patients, clinical examination is usually postponed after rewarming and suspension of sedation, that is, at about $72 \mathrm{~h}$ after ROSC or later[4]. For example, in a recent large trial on TTM in resuscitated comatose patients, prognostication was performed at a median of $118 \mathrm{~h}$ after cardiac arrest. [1]

In both TH-treated and non-TH-treated patients the most accurate clinical-based predictor at $\geq 72 \mathrm{~h}$ from ROSC is the absence of pupillary reflex to light (FPR 0\%). An absent corneal reflex is also usually associated with a poor outcome, but is slightly less specific than the pupillary reflex (FPR up to 5\%)[10,16-18]. Differently from the corneal reflex, the pupillary reflex is not influenced by the effect of muscle relaxants, since the constriction of pupils to light is achieved via the parasympathetic action to the sphincter pupillae. The sensitivity of ocular reflexes as prognosticators in coma after cardiac arrest is low, in fact only $20-30 \%$ of patients destined to a poor outcome show these signs. There is evidence that detection of pupillary response using clinical examination is relatively inaccurate[19]. Quantitative detection using a pupillometer may increase accuracy of this sign[20].

An absent or extension motor response to pain corresponding to a motor score 1 or 2 of the Glasgow Coma Scale ( $\mathrm{M} \mathcal{\Omega}$ ) at $\geq 72 \mathrm{~h}$ from ROSC is a sensitive, but non-specific sign of poor outcome (FPR 10-40\%)[6, 16, 18, 21]. Like the corneal reflex, the motor response can be suppressed by the effects of sedatives or neuromuscular blocking drugs [10].

Myoclonus is a clinical sign of central nervous system injury, which consists of sudden, brief, involuntary jerks caused by muscular contractions or inhibitions. Post-arrest myoclonus is a clinical phenomenon which may be associated or not with epileptiform activity on EEG [22]. A prolonged (>30 min) period of generalized unrelenting myoclonic jerks is defined as "status myoclonus". Early occurrence of status myoclonus in comatose resuscitated patients suggests a poor outcome [23, 24]. However, this should not be confused with Lance-Adams syndrome, a chronic form of postanoxic myoclonus which occurs in conscious patients, it is triggered by voluntary movements and it is often limited to the limb being moved (action myoclonus)[25]. Although Lance-Adams syndrome usually occurs late in the clinical course of post-anoxic cerebral injury, cases of early occurrence have been documented [26-28]. In resuscitated comatose patients with myoclonus the presence of sedation may make the detection of clinical consciousness difficult and create falsely pessimistic predictions[29]. 


\section{Electrophysiology}

Short-latency somatosensory evoked potentials (SSEPs) are among the most commonly used and robust predictors in post-anoxic coma. In non-TH-treated patients, a bilateral absence of the N20 SSEP wave predicts an invariably poor outcome as early as $24 \mathrm{~h}$ from ROSC[6, 30]. In TH-treated patients SSEP also perform well when recorded after rewarming[4]. The sensitivity of SSEPs is around 50\% when SSEPs are recorded after rewarming but is only $25 \%$ during $\mathrm{TH}$, partly because in some patients with an eventual poor outcome the N20 wave may be present during TH and subsequently disappear after rewarming [16].

Differently from clinical examination and EEG, SSEPs are less affected by sedative drugs or hypothermia that are typically used during the post arrest phase [31, 32]. However, in the ICU environment SSEPs are prone to interference coming from muscular artefacts and electrical equipment. For this reason, utmost care should be taken to maximize signal/noise ratio when recording SSEPs in these patients.

SSEPs are particularly prone to the bias of "self-fulfilling prophecy". In 10/12 (83\%) prognostication studies included in a recent review on prognostication after cardiac arrest[4] SSEP had been used as a criterion for withdrawal of life-sustaining treatment (WLST). One observational study [33] showed that results of SSEPs are more likely to influence physicians' and families' decision to withdraw life-sustaining therapies than those of clinical examination or EEG.

Electroencephalography has been among the first clinical investigations used to assess the severity of post-anoxic coma[34]. "Malignant" EEG patterns like low voltage or burstsuppression are usually associated to poor neurological outcome, both in TH-treated[35, 36] and in non-TH-treated patients[6, 37]. However, their systematic application as prognostic indexes has been hampered by the inconsistencies in their definition[3]. A recent standardization of EEG terminology from the American Clinical Neurophysiology Society [38] has not yet been incorporated into most of prognostication studies.

Absence of EEG reactivity to external stimuli has recently been described as a sensitive and highly specific index of poor neurological outcome, especially when detected after rewarming from TH (FPR 0\%; 95\%CI 0-3)[39, 40]. The major limitation of EEG reactivity is the lack of a standardization of the stimulus to be used. Moreover, this index has been described only in a limited number of studies made by expert electrophysiologists and it has never been validated in multicentre studies.

\section{Biomarkers}

The rationale of dosing markers of neuronal injury in the blood of resuscitated patients is that higher levels of biomarkers correlate with a higher extent of brain damage and consequently lower chances of recovery. The most widely used biomarkers for prognostication after cardiac arrest are neuron specific enolase (NSE) and the S-100 protein, which come from neurons and from astroglial and Schwann cells, respectively. Serum biomarkers NSE and S-100B have important theoretical advantages, such as ease of sampling and likely independence from the effects of sedative drugs. However, their thresholds for prediction of poor outcome with $0 \%$ FPR in resuscitated comatose patients 
vary largely. In non-TH-treated patients, these range from 15 to $90 \mu \mathrm{g} / \mathrm{L}$ at $72 \mathrm{~h}$ for NSE and from 0.12 to $0.8 \mu \mathrm{g} / \mathrm{L}$ for S-100[41-43]. For NSE in TH-treated patients, thresholds vary from 25 to $112.4 \mu \mathrm{g} / \mathrm{L}$ at $48 \mathrm{~h}[31,44]$ and from 57.2 and $78.9 \mu \mathrm{g}(\mathrm{L}$ at $72 \mathrm{~h}[45,46]$. Reasons for this variability include the presence of extracerebral sources of biomarkers. (red blood cells, neuroendocrine tumors and small-cell lung carcinoma for NSE, muscle and adipose tissue for S-100B,[47]) and the use of heterogeneous immunoenzyme measurement techniques.

Several considerations need to be taken with the use of biomarkers. Ideally, every clinical laboratory should validate its own biomarker thresholds for prediction of poor outcome after cardiac arrest. Performing multiple sampling of biomarkers during the first $72 \mathrm{~h}$ after ROSC and combining biomarkers with other indices appears at present as the most prudent strategy for using biomarkers in prognostication after cardiac arrest [48]. One mechanistic limitation of using these biomarkers is that they estimate cell injury irrespective of cell function.

Prognostication is linked to function, hence a future direction should be to develop biomarkers that not only provide reliable estimation of cell injury but also provide information of the types of brain cell function which will be more relevant to prognostication.

\section{Imaging}

Neuroimaging studies have only recently been investigated as indexes for prognostication in post-anoxic coma. In resuscitated comatose patients computer tomography (CT) of the brain is often performed to exclude other causes of cerebral injury or conditions like subarachnoid haemorrhage, which would contraindicate thrombolysis or anticoagulation[49]. On brain CT early postanoxic injury after cardiac arrest appears as a diffuse brain edema which can be quantified as the ratio between the densities of the grey matter and the white matter (GWR), measured in Hounsfield units. An average global GWR below 1.14 or a GWR below 1.22 at the level of basal ganglia on brain CT performed within one hour after ROSC predicted poor outcome with $100 \%$ specificity in two small cohort studies [50,51]. Similar results have been showed in other studies [21,52].

Neuronal cytotoxic edema on MRI is optimally detected using DWI sequences, especially at basal ganglia level and on posterior cortical areas [53]. The severity of injury on DWI can be quantified using apparent diffusion coefficient (ADC). Normal ADC values range between 700 and $800 \times 10-6 \mathrm{~mm} 2-\mathrm{s}-1$. [54] For prognostication purposes, a reduction of diffusion on MRI can be quantified using whole-brain ADC [55], the proportion of brain volume with low ADC[56] or the lowest ADC value in selected brain regions [57, 58]. The ADC thresholds for prediction of poor outcome with $0 \%$ FPR are inconsistent among prognostication studies [3, 4].

Imaging studies are not affected by sedation and paralysis and provide a topographic description of anoxic brain injury. However, their interpretation is more complex and less standardized than that of other prognostic indexes, and it may be affected by a significant interobserver variability. Moreover, they are not bedside tools. Execution of a MRI exam, in particular, may be problematic in more unstable patients. This may have caused a selection bias in most of prognostication studies on imaging, whose population size is generally small. 
Considering the limited quality of the available literature[59], caution has to be taken in using of imaging studies for prognostication after cardiac arrest. Currently they are recommended only in centers where a specific experience is available[48].

\section{Multimodal prognostication}

Even the most robust predictors, such as SSEP, do not guarantee an absolute certainty when predicting poor outcome, and cases of good neurological recovery in patients with multiple unfavorable characteristics have been reported [27]. For this reason, we recommend that prognostication should be multimodal whenever possible [48], i.e., it should be made using a combination of several different parameters (clinical examination, electrophysiology, biomarkers and imaging). There is evidence that this approach increases the accuracy of prediction $[60,61]$.

\section{Recommended prognostication strategy}

A prognostic evaluation should start with a thorough clinical examination[62]. This should be made after the phase of controlled temperature has been completed (patient is in normothermic state), and the sedative and muscle relaxant agents have been suspended from a sufficient time to avoid interference on clinical evaluation. This time would usually correspond to $72 \mathrm{~h}$ or more from ROSC, although some indicators can be evaluated earlier. The bilateral absence of either pupillary light reflex and/or the N20 SSEP wave suggests that a poor prognosis is very likely. If these tests are inconclusive, a combination of alternative tests like EEG, serum biomarkers, or imaging studies can be considered. If the results of prognostic tests produce conflicting results or prognostication remains uncertain, further clinical observation and re-evaluation is recommended [48]. In fact, most comatose resuscitated patients awake within one week from cardiac arrest [63, 64]. Up to $32 \%$ of comatose survivors treated with hypothermia who had a favorable neurologic outcome regained consciousness after 72 hours post rewarming [65].

\section{Conclusions}

In patients who are comatose after having been resuscitated after cardiac arrest early signs of unfavorable outcome (death, persistent vegetative state or severe neurological injury) include absent pupillary or corneal reflexes, early status myoclonus, burst-suppression or unreactive background on EEG, a bilaterally absent N20 SSEP wave, high blood levels of biomarkers, and diffuse signs of cytotoxic edema from ischemic brain injury on imaging studies. The mainstay of prognostication assessment is a careful clinical neurological examination, which should be made not earlier than $72 \mathrm{~h}$ from ROSC and only after major confounders have been excluded. Given the low sensitivity and imprecision of most predictors, a multimodal prognostication, depending on locally available tests and expertise, is recommended.

\section{Acknowledgments}

None

Financial support or sponsorship 
None

\section{References}

1. Nielsen N, Wetterslev J, Cronberg T, et al. Targeted Temperature Management at 33 degrees C versus 36 degrees C after Cardiac Arrest. N Engl J Med. 2013; 369:2197-2206. [PubMed: 24237006]

2. Brain Resuscitation Clinical Trial I Study Group. Randomized clinical study of thiopental loading in comatose survivors of cardiac arrest. N Engl J Med. 1986; 314:397-403. [PubMed: 2868412]

3. Sandroni C, Cavallaro F, Callaway CW, et al. Predictors of poor neurological outcome in adult comatose survivors of cardiac arrest: a systematic review and meta-analysis. Part 1: patients not treated with therapeutic hypothermia. Resuscitation. 2013; 84:1310-1323. [PubMed: 23811182]

4. Sandroni C, Cavallaro F, Callaway CW, et al. Predictors of poor neurological outcome in adult comatose survivors of cardiac arrest: a systematic review and meta-analysis. Part 2: Patients treated with therapeutic hypothermia. Resuscitation. 2013; 84:1324-1338. [PubMed: 23831242]

5. Perkins GD, Jacobs IG, Nadkarni VM, et al. Cardiac arrest and cardiopulmonary resuscitation outcome reports: Update of the Utstein resuscitation registry templates for out-of-hospital cardiac arrest. Resuscitation. 2015 in press.

6. Zandbergen EG, Hijdra A, Koelman JH, et al. Prediction of poor outcome within the first 3 days of postanoxic coma. Neurology. 2006; 66:62-68. [PubMed: 16401847]

7. Langhelle A, Nolan J, Herlitz J, et al. Recommended guidelines for reviewing, reporting, and conducting research on post-resuscitation care: the Utstein style. Resuscitation. 2005; 66:271-283. [PubMed: 16129543]

8. Dragancea I, Rundgren M, Englund E, et al. The influence of induced hypothermia and delayed prognostication on the mode of death after cardiac arrest. Resuscitation. 2013; 84:337-342. [PubMed: 23000363]

9. Mulder M, Geocadin RG. Uncertainties of death and dying in the era of therapeutic hypothermia: Impact on patient care and research. Resuscitation. 2013; 84:271-273. [PubMed: 23313423]

10. Samaniego EA, Mlynash M, Caulfield AF, et al. Sedation confounds outcome prediction in cardiac arrest survivors treated with hypothermia. Neurocrit Care. 2011; 15:113-119. [PubMed: 20680517]

11. Fukuoka N, Aibiki M, Tsukamoto T, et al. Biphasic concentration change during continuous midazolam administration in brain-injured patients undergoing therapeutic moderate hypothermia. Resuscitation. 2004; 60:225-230. [PubMed: 15036742]

12. Leslie K, Sessler DI, Bjorksten AR, Moayeri A. Mild hypothermia alters propofol pharmacokinetics and increases the duration of action of atracurium. Anesth Analg. 1995; 80:1007-1014. [PubMed: 7726398]

13. Caldwell JE, Heier T, Wright PM, et al. Temperature-dependent pharmacokinetics and pharmacodynamics of vecuronium. Anesthesiology. 2000; 92:84-93. [PubMed: 10638903]

14. Sandroni C, Cariou A, Cavallaro F, et al. Prognostication in comatose survivors of cardiac arrest: an advisory statement from the European Resuscitation Council and the European Society of Intensive Care Medicine. Intensive Care Med. 2014; 40:1816-1831. [PubMed: 25398304] This document reports the most recent guidelines on prognostication after cardiac arrest, produced by a multidisciplinary panel of specialists and based on Grading of Recommendations Assessment, Development and Evaluation (GRADE) criteria.

15. Okada KOS, Otani N, Sera T, Mochizuki T, Aoki M, Ishimatsu S. Prediction protocol for neurological outcome for survivors of out-of-hospital cardiac arrest treated with targeted temperature management. Resuscitation. 2012; 83:734-739. [PubMed: 22281226]

16. Bouwes A, Binnekade JM, Kuiper MA, et al. Prognosis of coma after therapeutic hypothermia: a prospective cohort study. Ann Neurol. 2012; 71:206-212. [PubMed: 22367993]

17. Cronberg T, Rundgren M, Westhall E, et al. Neuron-specific enolase correlates with other prognostic markers after cardiac arrest. Neurology. 2011; 77:623-630. [PubMed: 21775743]

18. Golan E, Barrett K, Alali AS, et al. Predicting Neurologic Outcome After Targeted Temperature Management for Cardiac Arrest: Systematic Review and Meta-Analysis. Crit Care Med. 2014; 
42:1919-1930. [PubMed: 24717465] The most recent systematic review on prognostication in patients treated with targeted temperature management.

19. Larson MD, Muhiudeen I. Pupillometric analysis of the 'absent light reflex'. Arch Neurol. 1995; 52:369-372. [PubMed: 7710372]

20. Suys T, Bouzat P, Marques-Vidal P, et al. Automated quantitative pupillometry for the prognostication of coma after cardiac arrest. Neurocrit Care. 2014; 21:300-308. [PubMed: 24760270]

21. Fugate JE, Wijdicks EF, Mandrekar J, et al. Predictors of neurologic outcome in hypothermia after cardiac arrest. Ann Neurol. 2010; 68:907-914. [PubMed: 21061401]

22. Thomke FMJJ, Sauer O, Hundsberger T, Hagele S, Wiechelt J, Weilemann SL. Observations on comatose survivors of cardiopulmonary resuscitation with generalized myoclonus. BMC Neurol. 2005; 5:14. [PubMed: 16026615]

23. Bouwes, AvPD.; Koelman, JH.; Kuiper, MA.; Zandstra, DF.; Weinstein, HC.; Tromp, SC.; Zandbergen, EG.; Tijssen, MA.; Horn, J. Acute posthypoxic myoclonus after cardiopulmonary resuscitation. BMC Neurol. 2012; 12:63. [PubMed: 22853736]

24. Rittenberger JC, Popescu A, Brenner RP, et al. Frequency and timing of nonconvulsive status epilepticus in comatose post-cardiac arrest subjects treated with hypothermia. Neurocrit Care. 2012; 16:114-122. [PubMed: 21638118]

25. Lance JW, Adams RD. The syndrome of intention or action myoclonus as a sequel to hypoxic encephalopathy. Brain. 1963; 86:111-136. [PubMed: 13928398]

26. Accardo J, De Lisi D, Lazzerini P, Primavera A. Good functional outcome after prolonged postanoxic comatose myoclonic status epilepticus in a patient who had undergone bone marrow transplantation. Case Rep Neurol Med. 2013; 2013:872127. [PubMed: 24368951]

27. Greer DM. Unexpected good recovery in a comatose post-cardiac arrest patient with poor prognostic features. Resuscitation. 2013; 84:e81-e82. [PubMed: 23454437]

28. English WA, Giffin NJ, Nolan JP. Myoclonus after cardiac arrest: pitfalls in diagnosis and prognosis. Anaesthesia. 2009; 64:908-911. [PubMed: 19604197]

29. Datta S, Hart GK, Opdam H, et al. Post-hypoxic myoclonic status: the prognosis is not always hopeless. Crit Care Resusc. 2009; 11:39-41. [PubMed: 19281443]

30. Madl C, Kramer L, Domanovits H, et al. Improved outcome prediction in unconscious cardiac arrest survivors with sensory evoked potentials compared with clinical assessment. Crit Care Med. 2000; 28:721-726. [PubMed: 10752821]

31. Tiainen M, Kovala TT, Takkunen OS, Roine RO. Somatosensory and brainstem auditory evoked potentials in cardiac arrest patients treated with hypothermia. Crit Care Med. 2005; 33:1736-1740. [PubMed: 16096450]

32. Kottenberg-Assenmacher E, Armbruster W, Bornfeld N, Peters J. Hypothermia does not alter somatosensory evoked potential amplitude and global cerebral oxygen extraction during marked sodium nitroprusside-induced arterial hypotension. Anesthesiology. 2003; 98:1112-1118. [PubMed: 12717132]

33. Geocadin RG, Buitrago MM, Torbey MT, et al. Neurologic prognosis and withdrawal of life support after resuscitation from cardiac arrest. Neurology. 2006; 67:105-108. [PubMed: 16832087]

34. Hockaday JM, Potts F, Epstein E, et al. Electroencephalographic Changes in Acute Cerebral Anoxia from Cardiac or Respiratory Arrest. Electroencephalogr Clin Neurophysiol. 1965; 18:575586. [PubMed: 14296835]

35. Rundgren M, Westhall E, Cronberg T, et al. Continuous amplitude-integrated electroencephalogram predicts outcome in hypothermia-treated cardiac arrest patients. Crit Care Med. 2010; 38:1838-1844. [PubMed: 20562694]

36. Cloostermans MC, van Meulen FB, Eertman CJ, et al. Continuous electroencephalography monitoring for early prediction of neurological outcome in postanoxic patients after cardiac arrest: a prospective cohort study. Crit Care Med. 2012; 40:2867-2875. [PubMed: 22824933]

37. Young GB, Doig G, Ragazzoni A. Anoxic-ischemic encephalopathy: clinical and electrophysiological associations with outcome. Neurocrit Care. 2005; 2:159-164. [PubMed: $16159058]$ 
38. Hirsch LJ, Laroche SM, Gaspard N, et al. American Clinical Neurophysiology Society's Standardized Critical Care EEG Terminology: 2012 version. J Clin Neurophysiol. 2013; 30:1-27. [PubMed: 23377439]

39. Rossetti AO, Carrera E, Oddo M. Early EEG correlates of neuronal injury after brain anoxia. Neurology. 2012; 78:796-802. [PubMed: 22323758]

40. Crepeau AZ, Rabinstein AA, Fugate JE, et al. Continuous EEG in therapeutic hypothermia after cardiac arrest: Prognostic and clinical value. Neurology. 2013; 80:339-344. [PubMed: 23284064]

41. Zingler VC, Krumm B, Bertsch T, et al. Early prediction of neurological outcome after cardiopulmonary resuscitation: a multimodal approach combining neurobiochemical and electrophysiological investigations may provide high prognostic certainty in patients after cardiac arrest. Eur Neurol. 2003; 49:79-84. [PubMed: 12584414]

42. Tiainen M, Roine RO, Pettila V, Takkunen O. Serum neuron-specific enolase and S-100B protein in cardiac arrest patients treated with hypothermia. Stroke. 2003; 34:2881-2886. [PubMed: 14631087]

43. Rosen H, Sunnerhagen KS, Herlitz J, et al. Serum levels of the brain-derived proteins S-100 and NSE predict long-term outcome after cardiac arrest. Resuscitation. 2001; 49:183-191. [PubMed: 11382525]

44. Huntgeburth M, Adler C, Rosenkranz S, et al. Changes in neuron-specific enolase are more suitable than its absolute serum levels for the prediction of neurologic outcome in hypothermiatreated patients with out-of-hospital cardiac arrest. Neurocrit Care. 2014; 20:358-366. [PubMed: 23836424]

45. Steffen IG, Hasper D, Ploner CJ, et al. Mild therapeutic hypothermia alters neuron specific enolase as an outcome predictor after resuscitation: 97 prospective hypothermia patients compared to 133 historical non-hypothermia patients. Crit Care. 2010; 14:R69. [PubMed: 20403168]

46. Storm C, Nee J, Jorres A, et al. Serial measurement of neuron specific enolase improves prognostication in cardiac arrest patients treated with hypothermia: a prospective study. Scand J Trauma Resusc Emerg Med. 2012; 20:6. [PubMed: 22284447]

47. Anderson RE, Hansson LO, Nilsson O, et al. High serum S100B levels for trauma patients without head injuries. Neurosurgery. 2001; 48:1255-1258. discussion 1258-60. [PubMed: 11383727]

48. Sandroni C, Cariou A, Cavallaro F, et al. Prognostication in comatose survivors of cardiac arrest: An advisory statement from the European Resuscitation Council and the European Society of Intensive Care Medicine. Resuscitation. 2014:1779-1789. [PubMed: 25438253]

49. Inamasu J, Miyatake S, Tomioka H, et al. Subarachnoid haemorrhage as a cause of out-of-hospital cardiac arrest: a prospective computed tomography study. Resuscitation. 2009; 80:977-980. [PubMed: 19581033]

50. Choi SP, Youn CS, Park KN, et al. Therapeutic hypothermia in adult cardiac arrest because of drowning. Acta Anaesthesiol Scand. 2012; 56:116-123. [PubMed: 22091986]

51. Kim SH, Choi SP, Park KN, et al. Early brain computed tomography findings are associated with outcome in patients treated with therapeutic hypothermia after out-of-hospital cardiac arrest. Scand J Trauma Resusc Emerg Med. 2013; 21:57. [PubMed: 23870424]

52. Metter RB, Rittenberger JC, Guyette FX, Callaway CW. Association between a quantitative CT scan measure of brain edema and outcome after cardiac arrest. Resuscitation. 2011; 82:1180-1185. [PubMed: 21592642]

53. Mlynash M, Campbell DM, Leproust EM, et al. Temporal and spatial profile of brain diffusionweighted MRI after cardiac arrest. Stroke. 2010; 41:1665-1672. [PubMed: 20595666]

54. Wijdicks EF, Campeau NG, Miller GM. MR imaging in comatose survivors of cardiac resuscitation. AJNR Am J Neuroradiol. 2001; 22:1561-1565. [PubMed: 11559506]

55. Wu O, Sorensen AG, Benner T, et al. Comatose patients with cardiac arrest: predicting clinical outcome with diffusion-weighted MR imaging. Radiology. 2009; 252:173-181. [PubMed: 19420318]

56. Wijman CA, Mlynash M, Caulfield AF, et al. Prognostic value of brain diffusion-weighted imaging after cardiac arrest. Ann Neurol. 2009; 65:394-402. [PubMed: 19399889] 
57. Kim J, Choi BS, Kim K, et al. Prognostic performance of diffusion-weighted MRI combined with NSE in comatose cardiac arrest survivors treated with mild hypothermia. Neurocrit Care. 2012; 17:412-420. [PubMed: 22932993]

58. Kim J, Kim K, Hong S, et al. Low apparent diffusion coefficient cluster-based analysis of diffusion-weighted MRI for prognostication of out-of-hospital cardiac arrest survivors. Resuscitation. 2013; 84:1393-1399. [PubMed: 23603152]

59. Hahn DK, Geocadin RG, Greer DM. Quality of evidence in studies evaluating neuroimaging for neurologic prognostication in adult patients resuscitated from cardiac arrest. Resuscitation. 2014; 85:165-172. [PubMed: 24231568] The largest available review on imaging studies for neuroprognostication after cardiac arrest, and on their limitations

60. Lee BK, Jeung KW, Lee HY, et al. Combining brain computed tomography and serum neuron specific enolase improves the prognostic performance compared to either alone in comatose cardiac arrest survivors treated with therapeutic hypothermia. Resuscitation. 2013; 84:1387-1392. [PubMed: 23792112]

61. Oddo M, Rossetti AO. Early multimodal outcome prediction after cardiac arrest in patients treated with hypothermia. Crit Care Med. 2014; 42:1340-1347. [PubMed: 24463859] This study on 134 resuscitated patients showed how a multimodal approach combining clinical examination, biomarkers and EEG reactivity can attain $100 \%$ specificity with a receiving operator characteristic area of 0.88 .

62. Sharshar T, Citerio G, Andrews PJ, et al. Neurological examination of critically ill patients: a pragmatic approach. Report of an ESICM expert panel. Intensive Care Med. 2014; 40:484-495. [PubMed: 24522878]

63. Gold B, Puertas L, Davis SP, et al. Awakening after cardiac arrest and post resuscitation hypothermia: are we pulling the plug too early? Resuscitation. 2014; 85:211-214. [PubMed: 24231569] This cohort study on 89 TTM- treated, comatose patients who regained consciousness after cardiac arrest showed that almost all comatose resuscitated patients awake within one week from ROSC.

64. Grossestreuer AV, Abella BS, Leary M, et al. Time to awakening and neurologic outcome in therapeutic hypothermia-treated cardiac arrest patients. Resuscitation. 2013; 84:1741-1746. [PubMed: 23916554]

65. Mulder M, Gibbs HG, Smith SW, et al. Awakening and withdrawal of life-sustaining treatment in cardiac arrest survivors treated with therapeutic hypothermia. Crit Care Med. 2014; 42:2493-2499. [PubMed: 25121961] 


\section{Key points}

- Prognostication in comatose survivors of cardiac arrest, although important, remains challenging.

- Most indexes used to predict poor outcome after cardiac arrest have limited precision and the relevant literature is potentially biased by lack of blinding, which may have caused a self-fulfilling prophecy.

- $\quad$ Predictors based on electroencephalogram and imaging are potentially useful, but need to be validated in multicentre studies using consistent definitions and methodologies.

- Prognostication should not be performed earlier than $72 \mathrm{~h}$ from ROSC and it should be multimodal whenever possible. Major confounders should be excluded. 